\title{
Simulation analysis of transportation system in Erzurum
}

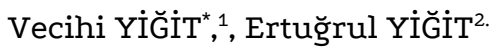 \\ ${ }^{1}$ Department of Industrial Engineering, Faculty of Engineering, Ataturk University, Erzurum, Turkey \\ ${ }^{2}$ Industrial Engineer, Erzurum Municipality, Erzurum, Turkey
}

\section{Keywords}

Transportation,

Transportation Systems,

Simulation,

ARENA.

\begin{abstract}
In recent years, the increase of population in cities has become one of the most important problems considered for municipalities providing transportation services. In terms of municipal services, the number of lines, capacity, and occupancy rates of public transportation vehicles providing transportation within the cities should be scientifically monitored and evaluated. In this study, we analyzed the current situation of municipal buses and public buses providing public transportation in Erzurum. For analyzing, we consider some performance criteria such as number of lines, capacity, vehicle occupancy rates, and passenger waiting. The current situation was modeled by simulation using the system approach. The interactions between entities are examined, sub-systems are identified, and the current situation is revealed. Results show that about 104.400 passengers benefit from public transportation daily, and performance criterias determined in the system are adequate.
\end{abstract}

\begin{abstract}
1.Introduction
In general, information and capital produced by people, the form, volume and scope of transportation, which means the transfer of goods and services, from one place to another, has been greatly expanded with the effect of increasing and constantly changing social and economic factors (Sandal 2009)[1]. Transportation has seen the necessary importance in all stages of human history and has been one of the most studied areas. Transportation, which has an important share in the establishment of civilizations in different parts of the world, has undoubtedly made significant contributions to the development and change of human history. Although there are many theories and approaches about the establishment and development of cities, one of the most important approaches is transportation (Aliağaoğlu 2010) [2] and transportation has played an important role in the formation of today's crowded cities. Specially, the impact of transport activities on the development and change of urban settlements cannot be underestimated (Tümertekin 1987) [3].
\end{abstract}

In recent years, migration from village to city has increased uncontrolled, and transportation in urban centers has been adversely affected. Due to population growth, the boundaries of the settlements have expanded and transportation has become an essential problem that is difficult to solve. There are several theories and approaches about the development of cities. One of these is transportation (Aliağaoğlu 2010) [4].

In the solution of transportation problems, efforts are made to spread the use of public transportation vehicles considering both environmental pollution and traffic congestion.

\subsection{The Aim and Scope of the Study}

Increasing number of vehicles due to development of cities unplanned public transport systems, has caused dissatisfaction with passengers, and wasted public resources. This is true for all major cities and is a valid problem for the province of Erzurum. When the public transportation system of Erzurum is examined, problems such as long line routes, bus occupancy rates vary widely, density at stops at work and departure times, excess passengers and waiting time at stops are observed. Based on the metropolitan municipality responsible for transportation in the city and central districts, the current situation was analyzed and the observed problems were examined by considering the performance criteria.

With the help of system analysis, the purpose, objectives, elements, parameters and variables of the system were determined by evaluating the current situation of municipal and private public buses from public transportation vehicles serving within the borders of EBB (city center and central districts). Using the system approach, the interactions between the elements were examined, sub-systems were identified, and the current situation was revealed. As a result, the system performance criteria such as vehicle occupancy rates, passenger waiting times and daily transportation costs were taken into consideration and the current situation was modeled by simulation. The modeled system was run in ARENA program and the problems in the current system were determined by considering the performance criteria determined by system analysis.

\subsection{Literature Search}

As a result of literature review, some studies related to public transportation systems are given in Table 1.1. Furthermore, the study has been added to the last line and its difference from the literature has been shown.

\section{Theoretical Foundations}

The dizzying development of technology in recent years has forced countries to compete economically with each other. Therefore, it is becoming more and more important for countries to plan and use their resources correctly. One of the most important factors in the resource use process is defined as any movement from one point to another in order to ensure the transfer of people, goods and / or goods between settlements. In particular, it is one of the most basic elements of human transport. Therefore, although there are many different areas of transport, this study focuses on human transport. 
Table 1.1.(Some studies on transportation)

\begin{tabular}{|c|c|c|c|}
\hline $\begin{array}{l}\text { Author Name } \\
\text { (Year of } \\
\text { publication) }\end{array}$ & Inputs & Outputs & Topic \\
\hline $\begin{array}{l}\text { Yllmaz } \\
(2005)[5]\end{array}$ & $\begin{array}{l}\text { - Number of } \\
\text { passengers } \\
\text { - Number of lines } \\
\text { - Number of vehicles - } \\
\text { station } \\
\text { - Line length }\end{array}$ & $\begin{array}{l}\text {-Transmission time } \\
\text { - Passenger waiting time } \\
\text { - Vehicle full rates } \\
\text {-line planning }\end{array}$ & $\begin{array}{l}\text { According to determined parameters, simulation of the public } \\
\text { transport was performed in the Crystal Ball program, the } \\
\text { current situation was removed, } 2 \text { different scenarios were } \\
\text { proposed, the parameters were improved, and line planning } \\
\text { was made. }\end{array}$ \\
\hline $\begin{array}{l}\text { Brueckner and } \\
\text { Selod (2006)[6] }\end{array}$ & $\begin{array}{l}\text { - urban public policy } \\
\text { decisions } \\
\text { - Homogeneous and } \\
\text { heterogeneous cities }\end{array}$ & $\begin{array}{l}\text {-time } \\
\text {-cost }\end{array}$ & $\begin{array}{l}\text { Comparing the transport system for homogeneous and } \\
\text { heterogeneous cities, considering urban public policies and } \\
\text { land ownership an optimal model is proposed. }\end{array}$ \\
\hline $\begin{array}{l}\text { Damart and } \\
\text { Roy(2009)[7] }\end{array}$ & $\begin{array}{l}\text {-Air pollution } \\
\text {-noise pollution } \\
\text {-public resources }\end{array}$ & $\begin{array}{l}\text {-cost, benefit analysis - } \\
\text { socioeconomic impact on } \\
\text { investment of public } \\
\text { resources }\end{array}$ & $\begin{array}{l}\text { Cost-benefit analysis of public resources has been made by } \\
\text { considering air and noise pollution which are environmental } \\
\text { factors in public transportation decisions. }\end{array}$ \\
\hline $\begin{array}{l}\operatorname{Lin} \\
(2010)[8]\end{array}$ & $\begin{array}{l}\text { - time constraint } \\
\text {-cost } \\
\text {-capacity }\end{array}$ & $\begin{array}{l}\text {-Transport system } \\
\text { performance } \\
\text { - Quality level } \\
\text { - Transportation complexity }\end{array}$ & $\begin{array}{l}\text { They proposed a new algorithm to evaluate the performance of } \\
\text { stochastic transport systems. The proposed algorithm was } \\
\text { applied for factories in } 4 \text { different cities and the quality level } \\
\text { was measured. }\end{array}$ \\
\hline $\begin{array}{l}\text { Hatipoğlu and } \\
\text { Öztürk } \\
(2012)[9]\end{array}$ & $\begin{array}{l}\text {-public transport } \\
\text { - density of private } \\
\text { vehicles during peak } \\
\text { hours }\end{array}$ & $\begin{array}{l}\text { - Trip demand forecast } \\
\text { - Vehicle sharing system } \\
\text { and tele work }\end{array}$ & $\begin{array}{l}\text { They have developed travel demand method strategies to } \\
\text { reduce the number of private vehicles during peak hours in the } \\
\text { institution where the number of office workers is determined } \\
\text { and the start and end hours are busy. }\end{array}$ \\
\hline $\begin{array}{l}\text { Sawicki and } \\
\text { Zak(2013)[10] }\end{array}$ & $\begin{array}{l}\text {-Transport } \\
\text { infrastructure } \\
\text {-Technical equipment } \\
\text {-Organization rule }\end{array}$ & $\begin{array}{l}\text {-customer happiness - level } \\
\text { of meeting customer } \\
\text { requirements }\end{array}$ & $\begin{array}{l}\text { It measures the level of meeting the customer needs by making } \\
\text { transportation classification in the light of the data obtained by } \\
\text { using dominance based coarse set theory method. }\end{array}$ \\
\hline $\begin{array}{l}\text { Solecka and Zak } \\
(2014)[11]\end{array}$ & $\begin{array}{l}\text {-Transport } \\
\text { infrastructure } \\
\text { - Transportation } \\
\text { usage rate } \\
\text {-cost }\end{array}$ & $\begin{array}{l}\text { - Transport types } \\
\text { integration -performance } \\
\text { criteria }\end{array}$ & $\begin{array}{l}\text { Designing transport solutions that result in the integration of } \\
\text { an urban public transport system } \\
\text { and the general methodology for their evaluation. }\end{array}$ \\
\hline $\begin{array}{l}\text { Milevich et al. } \\
(2016)[12]\end{array}$ & $\begin{array}{l}\text { - road network } \\
\text { modeling - Population } \\
\text { synthesis data }\end{array}$ & $\begin{array}{l}\text { - Analysis of the transport } \\
\text { zone }\end{array}$ & $\begin{array}{l}\text { Planning of } 2018 \text { World Cup semi-final match } \\
\text { entrance and exit of the traffic from stadium have occurred. }\end{array}$ \\
\hline $\begin{array}{l}\text { Özuysal and } \\
\text { Gülhan } \\
(2017)[13]\end{array}$ & $\begin{array}{l}\text {-Traffic perspective } \\
\text { - factors affecting } \\
\text { accessibility }\end{array}$ & $\begin{array}{l}\text { - Transportation planning } \\
\text { policy } \\
\text { - Transportation system } \\
\text { performance }\end{array}$ & $\begin{array}{l}\text { Definition of accessibility approach as a measure of } \\
\text { transportation system performance, mission and sees the } \\
\text { advantages that other approaches provide. }\end{array}$ \\
\hline $\begin{array}{l}\text { This study } \\
\text { (2019) }\end{array}$ & $\begin{array}{l}\text { - Number of } \\
\text { passengers } \\
\text { - Number of lines } \\
\text { - Number of vehicles } \\
\text {-station }\end{array}$ & $\begin{array}{l}\text {-Passenger waiting time } \\
\text {-cost } \\
\text { - Vehicle occupancy rates }\end{array}$ & $\begin{array}{l}\text { In the light of the determined performance criteria, the } \\
\text { simulation of public transport was performed in the Arena } \\
\text { program and the current situation was revealed and the } \\
\text { problems in the system were determined. }\end{array}$ \\
\hline
\end{tabular}

Public transportation is the general name of the transportation systems that can be used by everyone that has a certain route and price tariff in order to provide transportation between people in and out of the city. The aim of public transportation systems is to make the most economical and shortest time to reach people in order to reduce the traffic density. It has become an important situation that cities and countries should plan public transport and increase their competitiveness in terms of their contribution to economy, human health, energy efficiency and environment. Cities and countries that work more on public transport have always been one step ahead of others. The mode of transportation varies between states in the United States, still rail and bus systems are widely used. In Europe, it is observed that bus systems and rail systems are used frequently, especially in England and Germany, as well as bicycle and pedestrian transportation is preferred especially in the Netherlands and Denmark. In the Far East countries, Korea and Singapore, rail systems are used extensively. In addition, bus systems support rail systems (Cirit 2014) [14]. As shown in Figure 2.1, the use of rail systems and daily passenger numbers in some metropolises are given.

In our country, although the metropolitan rail and bus systems are used predominantly, the percentage of bus system usage is higher. In other cities, the bus system is used and work is being carried out in order to switch to the rail system.

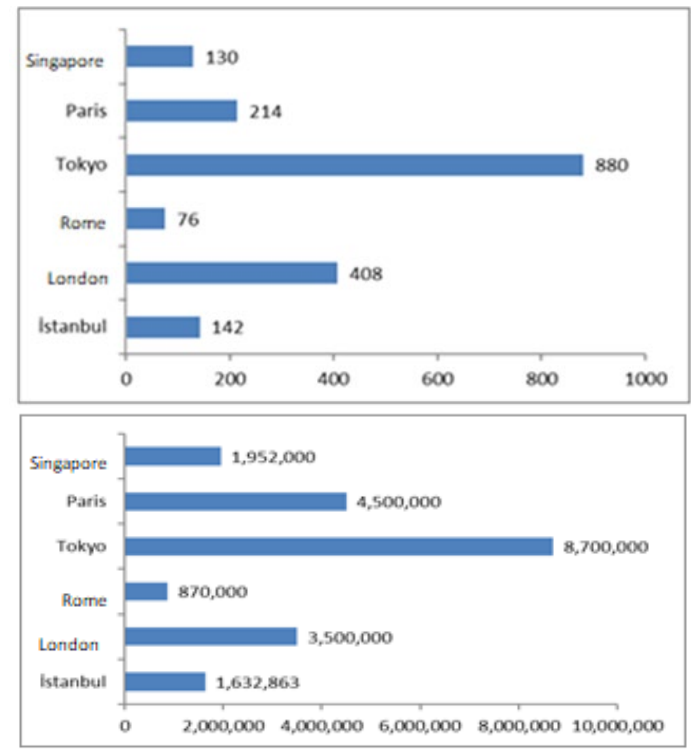

Figure 2.1. (Use of rail system (left)and length of rail system (right) in some metropolises $(\mathrm{km}))$ 
Turkey's largest and most advanced subway in Istanbul with the transport network, light rail, tram, cable car, but also the rail system, such as the funicular and Marmaray bus system and the sea route has different alternative modes of transport such as system.

The railway system serves approximately 2.7 million people daily, approximately 11.7 million daily by road transport such as buses, minibuses, taxis and shuttles, and approximately 500,000 daily by sea transportation. There are 11,795 stops and 2756 buses in the bus system, which is mainly used (IETT, 2019) [15]. The Metropolitan Municipality buses, private public buses and minibuses provide public transport in Erzurum province. There are 6 different lines of minibuses and 95 minibuses serve in these lines. There are 35 different lines in the buses and a total of 249 buses operate in these lines. 80 of 249 buses belong to EBB and the remaining 169 buses belong to persons. In this study, the buses that are subject to the Kardelen card system examined. Although the number of passengers served during the week is between 105-120 thousand per day, this number decreases to approximately 70 thousand at the weekend.

\section{Material and Method}

The system approach is a perspective and behavior that uses the system analysis in this process to understand and evaluate the subsystems that make up the whole system and the relations between them to solve the problems that will occur in the system (Koçel 1982) [16]. In addition, it can be defined as the point of view that all the subelements are taken into consideration when examining the problems identified and that makes this problem understood (Aydın 1988) [17] The system approach, which assists in decision-making, is a method that enables decision-makers to see the problems on the system under uncertainty by examining the system.

In this sense, the system analysis involves the best definition of the identified objectives and the identification of alternative scenarios to achieve these objectives. System analysis is used in the planning and programming of defense systems as well as in other areas where it is desirable to develop social systems through scientific means. General system theory includes some rules that classify the relationship between systems in and around themselves and govern the behavior of classes. It is the process of developing a mathematical and logical model of the system and producing different scenarios on this model in order to predict the result of the change in the system which is more cost-effective in terms of the determined time cost. Simulation is a process that enables us to obtain unbiased information about the processes that are available today, and more importantly, that may be available tomorrow. When we consider a reallife system, it refers to a process in which the input and output of the system and other elements are taken into consideration where the results of different decisions taken on a model can be applied and the results can be examined as it saves time and money. Provides the possibility to produce scenarios on the system by simulating the system one by one in order to make predictions about the system and determine the decisions based on implementation with the data obtained.

When analyzing a system or trying to solve a problem, simulation is one of the best methods for presenting the current situation, identifying the problems and producing alternative solutions as a result of the problems. In addition, it provides a very convenient solution in terms of time and cost in analyzing complex systems and solving problems. All scenarios that are wanted to be tested in the real system can be tried on the model in a short time and the results can be analyzed. Therefore, simulation method was preferred in this study in order to better observe the problems in the public transportation system of Erzurum.

\section{Research Findings}

In our study, in order to determine problems of the current system of transportation system in Erzurum province, input, output, purpose, objectives and elements of the current system were taken into consideration while the more specific elements for simulation were taken into consideration in order to obtain effective results. From this point of view, passengers, lines, buses and stops are identified as inputs to the system. The aim of the system is to minimize the waiting time and the number of waiting passengers and ensure the optimum cost of the system in addition to quality and comfortable transportation while meeting the transportation demand of the people requesting travel.

The objective of the system is to ensure that the system achieves its purpose and to make transportation planning that will increase the rate of passengers using public transportation in order to reduce air pollution and traffic density. The aim of the system seems to be related to each other. As the aim of the system is realized, the objective of the system will be realized in time.

The elements of the system are passengers, buses, drivers, stops, lines, card system, transportation department, snowdrop card management and other vehicles. Interactions exist between the elements of the system. The determination of the lines is carried out by the Department of Transportation. The number of laps which vehicle will carry on which line and the fare to be charged to the passengers are determined here. The waiting times of the passengers depend on the determined line route and lap time. As can be seen, there is interaction between the elements. The number of lines, number of vehicles and number of passengers are the system parameters, vehicle occupancy rates, number of passengers waiting at the stops and waiting time at the stops constitute the system performance criteria. As the output of the system, the transportation demand met and the transportation cost was determined.

\subsection{Current Situation Analysis}

With the study, the places where the bus lines crossed were examined and 250 different stops were identified after some of the close stops were combined. Other data required for simulation of the system were obtained from Erzurum Metropolitan Municipality Department of Transportation and Kardelen Card Directorate. One of the observed problems in general is the length of the line.

This is true for many lines and the length of the B2 and G3 lines is shown in Figure 4.1 and Figure 4.2 for understanding. Inter-stop times are determined in seconds for each line route. The one-hour chart obtained from the Kardelen Card Directorate was examined and the weight coefficient was established for the 250 stops determined. Passengers getting on and off were determined by taking into consideration the weight coefficients.

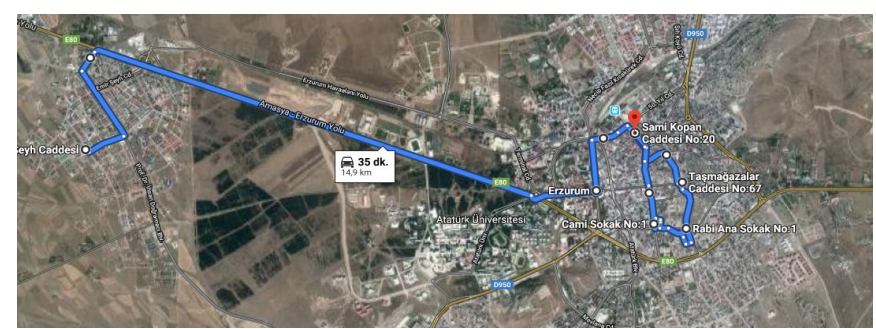

Figure 4.1. B2 line route

\subsubsection{Stops and codes used in the program}

The urban transportation network of Erzurum province was examined and the route where 35 lines crossed and the stops they stopped were determined. Some of the stops that are close to each other are considered as one stop and they are named after their location, street or street. For the convenience of the program, the station names were formed according to the alphabetical order of the letter D representing the coding stop and the letter number ' 1 representing the order. 


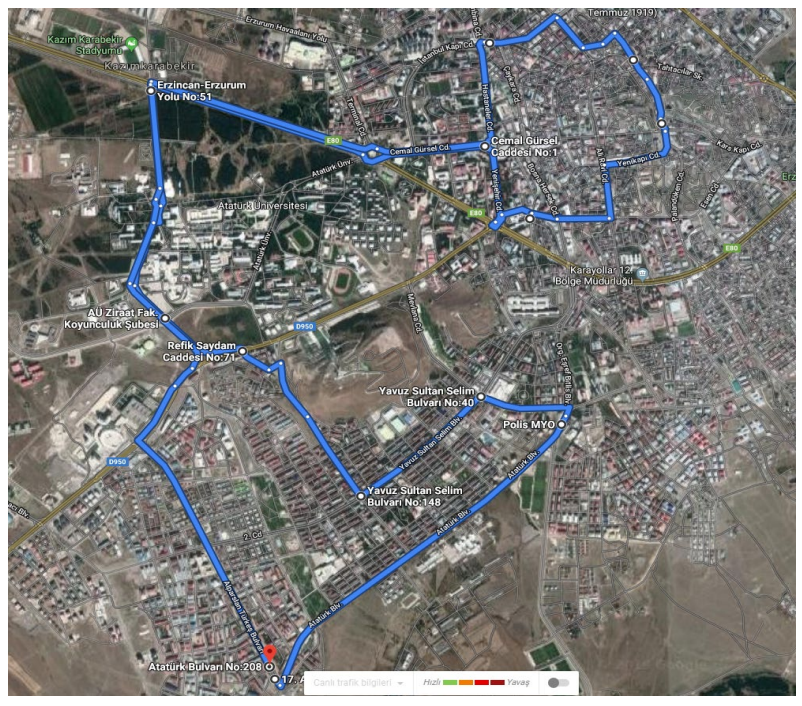

Figure 4.2. G3 line route

\subsubsection{Lines and routes}

There are a total of 35 lines in the card system that provides transportation in Erzurum. 12 of these lines are the northern line and are represented by the letter K. 14 of them are the southern line and are represented by the letter G. 8 is the western line and is represented by the letter B. Lastly, one of them is the eastern line and is represented by the letter $\mathrm{D}$. The round-trip routes and stops of these lines have been taken from the Kardelen Card Directorate and simulated in the arena program.

\subsubsection{Number of times between stops and number of passengers}

The lap times of the lines and the elapsed time between stops were received from the snowdrop card management and the times for some combined stops in the system were revised. The revised times are entered into the simulation program.

\subsubsection{Station weight coefficients}

While determining the number of passengers landing at the stops, the passengers arriving as a result of the passenger records taken from the Kardelen card serving within the EBB and the observations made were created in tables for the stops where each line passes. The scoring system was used according to the number of passengers descending and the number of lines passing through the stops. When calculating weight coefficients at the stops, as a result of the Kardelen card data, the calculation of the number of passengers' lines passing from that station was reduced to one time was given numerical points.

Table 4.1. Station weight coefficient calculation method

\begin{tabular}{|c|c|}
\hline Single Passenger Interval Range & Numerical Score \\
\hline Between 0-30 & 1 \\
\hline Between 31-50 & 2 \\
\hline Between 51-80 & 3 \\
\hline Between 81-100 & 4 \\
\hline Between 101-120 & 5 \\
\hline Between 121-140 & 6 \\
\hline Greater than 140 & 7 \\
\hline Number of Lines & Numerical Score \\
\hline$<=7$ & 0 \\
\hline$>7$ & 1 \\
\hline \multicolumn{2}{|c|}{$\begin{array}{l}\text { Station Weight Coefficient }=\text { Number of Passengers Landing at the } \\
\text { Station }+ \text { Number of Lines Passing from the Station }\end{array}$} \\
\hline
\end{tabular}

The number of the descending passengers was examined and a numerical score was given according to the concentration of the descending passengers at the stops. In addition, considering the number of lines passing the station, the weight coefficient was calculated for each station. Weight coefficient calculation is shown in Table 4.1.

\subsubsection{Passenger numbers in March}

Data obtained from EBB Kardelen card is taken as hourly chart in daily passenger numbers in March 2018. The hourly charts of the stops for the lines have been formed by the determined weight coefficients. Average monthly number of passengers is given in Table A1 of ANNEX A.

\subsubsection{Simulation of the current situation in the arena program}

First of all, 250 stops and separate queues have been created for each line passing through the stops. Passengers arriving at the stops are derived from hourly schedules as a result of the available data. Passengers arriving for the lines passing through the stops are queued according to the percentage slices obtained from the data. In the system, $14 \mathrm{G}$ lines, $12 \mathrm{~K}$ lines, $8 \mathrm{~B}$ lines and $1 \mathrm{D}$ lines were simulated. The current system is modeled in the Arena Program. The program view is given in Figure $\mathrm{A} 1$ in ANNEX A. In Figure 4.3, animation image of the $\mathrm{B} 8$ line is given.

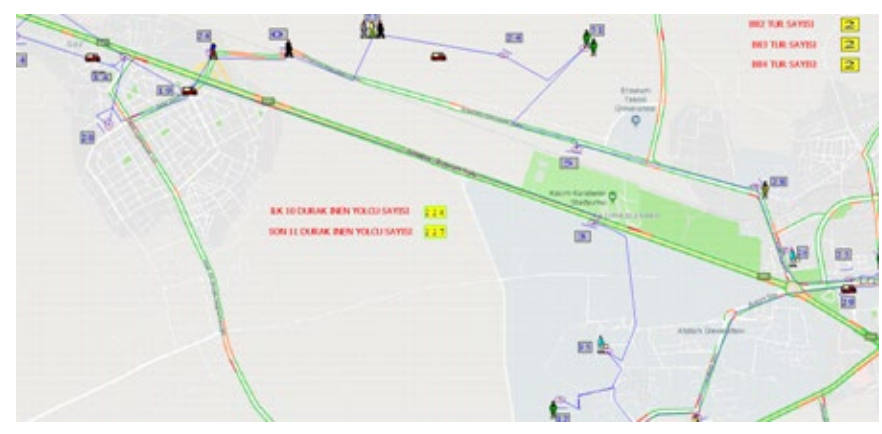

Figure 4.3. B8 line animation view

\section{Conclusions and Recommendations}

When the program output was examined, 104.400 passengers benefit from public transportation daily. Program reports were based on considering system performance criteria determined for all stops and all lines. The performance criteria determined in the system are shown in Appendix A Table A2, some of the waiting number values are shown in Appendix A Table A3 and waiting time at stops are shown in Appendix A Table A4. Program outputs and some data shown through snowdrop card is another system performance called the vehicle occupancy value which is shown in Appendix A table A5. While simulating the system, we take into consideration passenger waiting time, number of waiting and occupancy status reports, When the system outputs are examined it is observed that the lines with longer waiting times have generally higher queue than the other lines, When the long queues were examined it is observed that the number of lines passing through the station is low for some stops and the number of lines passing in the direction of the route where transportation is high is low. By reviewing the current situation, vehicle occupancy rates were compared and the densities of the lines were determined. In the current model, the daily fuel price is calculated as $146.550,94 \mathrm{TL}$. While calculating the cost, the average daily route in the system is calculated as $236 \mathrm{~km}$ and the calculation is made for both diesel bus and CNG (compressed natural gas) bus and given in Appendix A Table A6. By taking into consideration the current performance criteria, in order to solve the problems observed or to improve the determined performance criteria, advancing studies can be carried out on alternative models. 


\section{Declaration of Conflict of Interests}

The authors declare that there is no conflict of interest. They have no known competing financial interests or personal relationships that could have appeared to influence the work reported in this paper.

\section{References}

[1.] Sandal, E. K., Transportation Problems and Public View about Transportation System and Problems in Kahramanmaras. Journal of Doğu Coğrafya, 14(21) (2009) 137-157.

[2.] Tümertekin, E., Transportation geography. Istanbul University Geography Institute Publication (1987).

[3.] Aliağaoğlu, A. ve Uğur, A., Urban Geography. Nobel Akademik Yayıncilık, Ankara (2010).

[4.] Yllmaz, E., A new model for urban bus transportation nd performance evoluation with Simulation techniques. Öneri Dergisi 6 (2005) 161-173.

[5.] Brueckner, J.K., Selod, H., The Political Economy of Urban Transport System Choice. Journal of Public Economics 90 (2006) 983-1005.

[6.] Damart, S., Roy, B., The Uses Cost Benefit Analysis in Public Transportation Decision Making in France. Transport policy 16 (2009) 200-212.

[7.] Lin, Y. K., Novel Algoritihm To Evalate The Performance of Stochastic Transportation System. Expert Systems with Applications 37 (2010) 968-973.
[8.] Hatipoğlu, S., Öztürk, E.A., An Application On The Effect Of Travel Demand Management Strategies On Urban Traffic Load. Sakarya University Journal of Science 16 (2012) 62-68.

[9.] Sawicki, P., Zak, J., The Application Of Dominance Based Rough Sets Theory To Evaluation of Transportation System. Procedia Social and Behavioral Sciences 111 (2013) 1142-1154.

[10.] Solecka, K., Zak, J., Integration of The Urban public Transportation System with The Application of Traffic Simulation. Transportation Research Procedia 3 (2014) 259-268.

[11.] Milevich, D., Melnikov, V., Karbovskii, V., Krzhizhanovskaya, V. Simulating An Impact Of Road Network Improvements on The Performance of Transportation Systems under critical Load: Agent Based Approach. Procedia Computer Science 101 (2016), 253-261.

[12.] Görkem, G., Ozuysal, M., A novel decision-making support model based on value of time for public transport planning. Proceedings of the Institution of Civil Engineers-Transport. 173, 1 (2020). \& İMO Dergisi (2017)

[13.] Cirit, F., Sustainable Urban Transport Policies and Comparasion of Mass Transit System. T.C. kalkınma Bakanlığı \& IETT, Pub. No: 2891 (2019).

\section{How to Cite This Article}

Yiğit, V., Yiğit, E., Simulation analysis of transportation system in Erzurum, Brilliant Engineering, 2(2021), 20-30. https://doi.org/10.36937/ben.2021.002.003. 


\section{APPENDIX A}

Table A1. Average Monthly Passengers

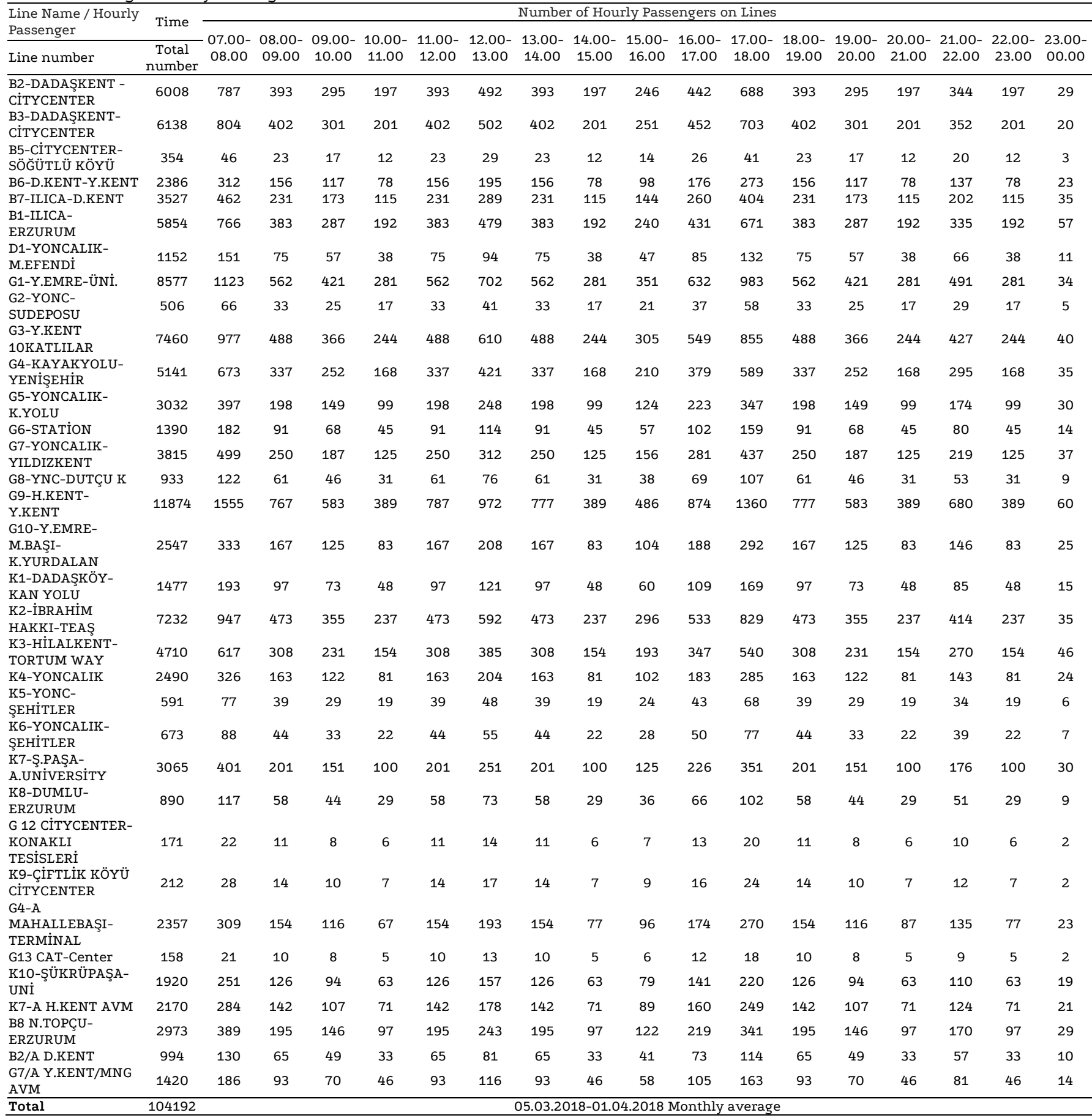




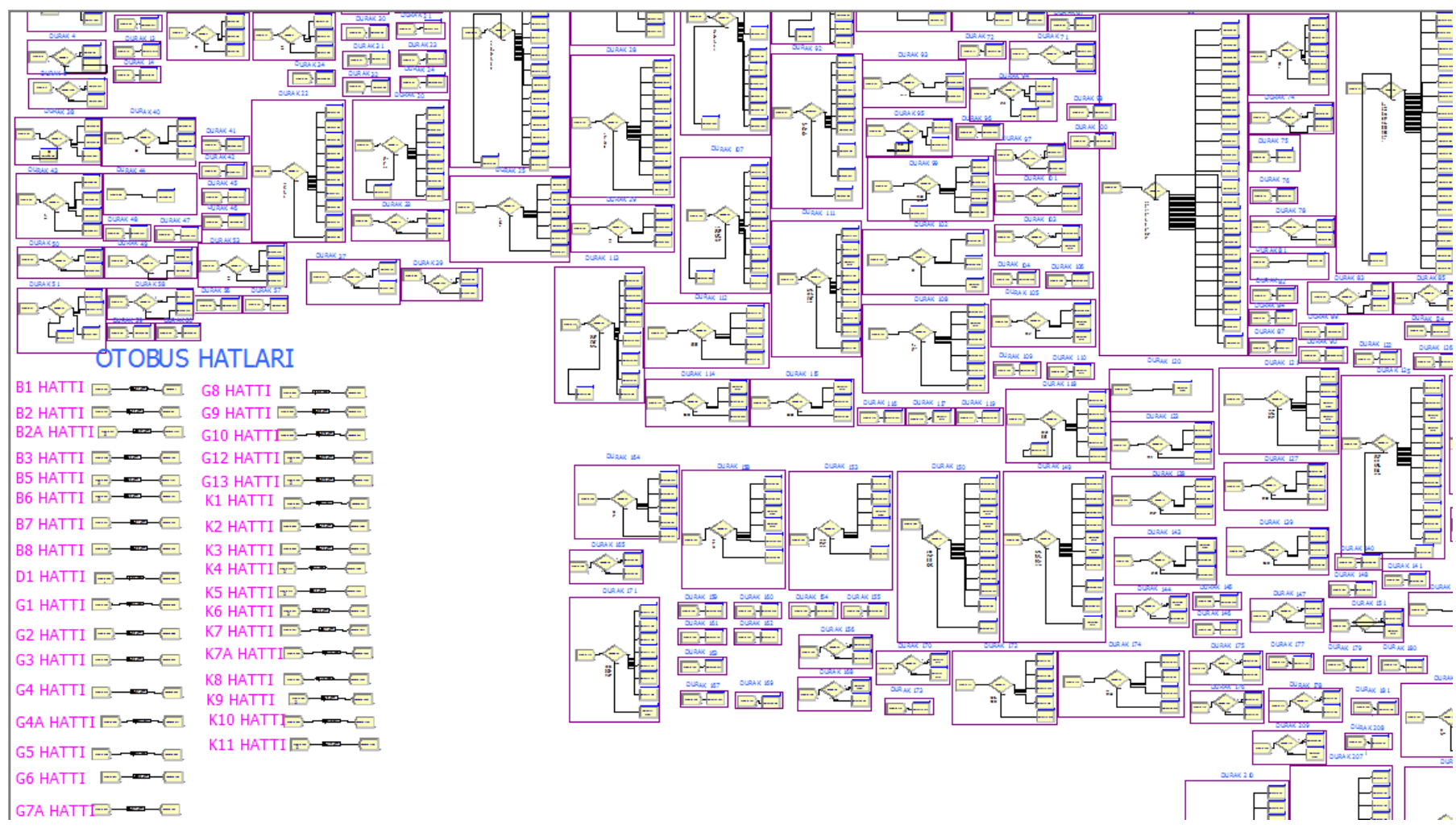

Figure A1. Arena Program Overview (G2 Line)

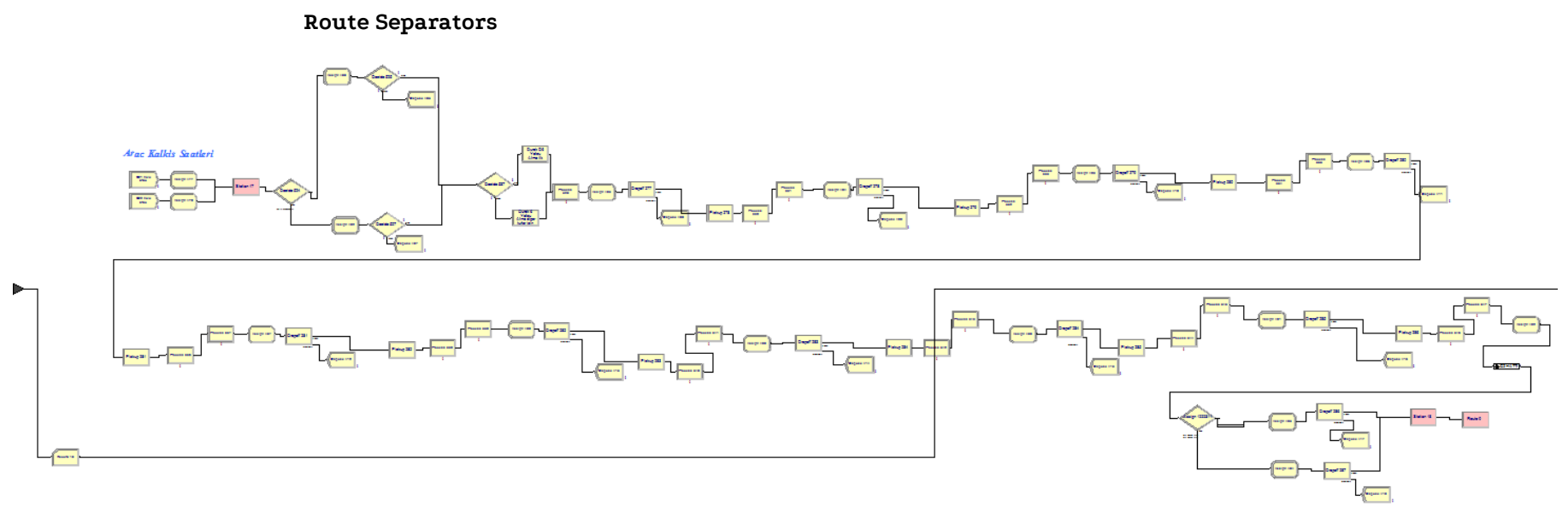

Figure A2. Arena Program G2 Line Simulation View 
Table A2. Waiting Time of Passengers in the Station

\begin{tabular}{|c|c|c|c|c|c|c|c|}
\hline $10: 45: 15$ & \multicolumn{4}{|c|}{ Category Overview } & & \multicolumn{2}{|c|}{ Ekim 9, 2018} \\
\hline \multicolumn{8}{|l|}{ Unnamed Project } \\
\hline Reppllcations: & TIme Units: & Hours & & & & & \\
\hline \multicolumn{8}{|l|}{ Queue } \\
\hline \multicolumn{8}{|l|}{ Time } \\
\hline Waring TIme & & Aversoge & Hair Wieth & $\begin{array}{l}\text { Minimum } \\
\text { Aversoge }\end{array}$ & $\begin{array}{l}\text { Maximum } \\
\text { Averoge }\end{array}$ & $\begin{array}{c}\text { Minimum } \\
\text { value }\end{array}$ & $\begin{array}{c}\text { Maximum } \\
\text { value }\end{array}$ \\
\hline Durak12 B3. Cueve & & 0.1688 & 0,01 & 0.1427 & 0.1911 & 0.00013238 & 0.9356 \\
\hline Durak120 G4A Cueve & & 0.1799 & 0.00 & 0.1799 & 0.1799 & 0.01361111 & 0.4014 \\
\hline Durak121 D1.Cueve & & 0.1497 & 0,01 & 0.1236 & 0.1776 & $0.0000841 \varsigma$ & 0.4915 \\
\hline Durak121 G10 Cueve & & 0.1385 & 0,00 & 0.1280 & 0.1551 & $0.0003549:$ & 0.2628 \\
\hline Durak121 G2 Cueve & & 0.1820 & 0.01 & 0.1603 & 0.2091 & 0.00146438 & 0.4616 \\
\hline Durak121 G4A Cueve & & 0.1145 & 0,01 & 0.1031 & 0.1300 & 0.0000783 & 0.4164 \\
\hline Durak121 K5.Cueve & & 0.1593 & 0.01 & 0.1287 & 0.1845 & $0.0013815:$ & 0.4997 \\
\hline Durak121 K6.Cueve & & 0.1395 & 0.01 & 0.1191 & 0.1707 & 0.00036044 & 0.5361 \\
\hline Durak122 D1. Cueve & & 0.1837 & 0,00 & 0.1837 & 0.1837 & 0.00594444 & $0.488:$ \\
\hline Durak123 G5 Cueve & & 0.08692619 & 0,01 & 0.07488046 & 0.0990 & 0.00011938 & 06582 \\
\hline Durak123 G6. Cueve & & 0.1880 & 0,02 & 0.1582 & 02246 & 0.00074226 & 0.4798 \\
\hline Durak123 G7. Cueve & & 0.04321125 & 0,00 & 0.03969222 & 0.04758658 & 0.00003642 & 02466 \\
\hline Durak124 G3 Cueve & & 0.04986041 & 0,00 & 0.04986041 & 0.04986041 & 0.00027778 & 0.4436 \\
\hline Durak125 B1. Cueve & & 0.1051 & 0,00 & 0.0964 & 0.1130 & 0.00023646 & 0.3544 \\
\hline Durak125 B3.Cueve & & 0.04276403 & 0,00 & 0.03356304 & 0.05181840 & 0.00000656 & 0.4185 \\
\hline Durak125 B5. Cueve & & 0.5227 & 0,04 & 0.3878 & 0.5968 & $0.0041054 E$ & 1.1862 \\
\hline Durak125 G1. Cueve & & 0.05285212 & 0,00 & 0.04694127 & 0.06078216 & $0.0000362:$ & 0.4594 \\
\hline Durak125 G12 Cueve & & 0.6886 & 0,12 & 0.4943 & 1.0595 & 0.01309625 & 1.6625 \\
\hline Durak125 G13. Cueve & & 0.5887 & 0,10 & 0.3156 & 0.7734 & $0.0098740 \mathrm{~K}$ & 1.3805 \\
\hline Durak125 K1. Cueve & & 0.2098 & 0,01 & 0.1811 & 02460 & 0.00107446 & 0.4951 \\
\hline Durak125 K11. Cueve & & 0.4381 & 0,03 & 0.4326 & 0.5653 & 0.00796562 & 0.9911 \\
\hline Durak125 K3. Cueve & & 0.2679 & 0,02 & 0.2143 & 0.3141 & 0.00008836 & 1.4646 \\
\hline Durak125 K4 Cueve & & 0.2018 & 0,02 & 0.1537 & 02580 & $0.0024709:$ & 1.0752 \\
\hline Durak125 K7. Gueve & & 0.3178 & 0,02 & 0.2844 & 0.3603 & 0.00017055 & 1.3966 \\
\hline Durak125 K8. Cueve & & 0.2394 & 0,02 & 0.2066 & 0.2837 & $0.0003076:$ & 0.4971 \\
\hline Durak125 K9 Cueve & & 0.5931 & 0,09 & 0.3999 & 0.8472 & 0.01393212 & 1.2796 \\
\hline Durak125 B6.Cueve & & 0.2802 & 0,00 & 0.2802 & 0.2802 & 0.00916667 & 1.0092 \\
\hline Durak127 B2. Cueve & & 0.08514474 & 0.01 & 0.07245409 & 0.1003 & 0.00002345 & 0.8702 \\
\hline Durak127 B3.Cueve & & 0.03392134 & 0,00 & 0.03059790 & 0.03685102 & 0.00004028 & 0.2884 \\
\hline Durak127 G1. Cueve & & 0.05477052 & 0,00 & 0.04653994 & 0.06338375 & 0.00009432 & 0.4928 \\
\hline Durak128 B3. Cueve & & 0.02089619 & 0,00 & 0.02024638 & 0.02187648 & $0.0000000 \mathrm{C}$ & 0.0664444 \\
\hline Durak128 B5. Cueve & & 0.2573 & 0.04 & 0.2051 & 0.4039 & 0.00161111 & 06598 \\
\hline Durak128 B6. Cueve & & 0.1650 & 0.01 & 0.1555 & 0.1762 & 0.00044444 & 0.4875 \\
\hline Durak129 B2A Cueve & & 0.1504 & 0.01 & 0.1339 & 0.1756 & 0.00009722 & 0.8079 \\
\hline Durak129 G4 Cueve & & 0.3241 & 0,03 & 0.2755 & 0.4096 & 0.00029697 & 1.7937 \\
\hline Durak129 G4A Cueve & & 0.1968 & 0.01 & 0.1201 & 02154 & 0.00001428 & 0.8057 \\
\hline Durak129 G7A Cueve & & 0.05120727 & 0,00 & 0.05533870 & 0.07214199 & 0.00000345 & 0.5695 \\
\hline Durak129 K10 Cueve & & 0.05754909 & 0,00 & 0.05281243 & 0.06305076 & 0.00007876 & 0.3515 \\
\hline Durak129 K3. Cueve & & 0.1506 & 0,01 & 0.1349 & 0.1683 & 0.00007716 & 0.9724 \\
\hline Durak129 K4 Cueve & & 0.1317 & 0,01 & 0.1211 & 0.1402 & 0.00003391 & 0.5097 \\
\hline Durak129 K9. Cueve & & 0.3405 & 0,03 & 0.2849 & 0.3964 & 0.00193611 & 0.8536 \\
\hline
\end{tabular}


Table A3. Number of Passengers Waiting at Station

\begin{tabular}{|c|c|c|c|c|c|c|c|}
\hline $10: 45: 15$ & \multicolumn{4}{|c|}{ Category Overview } & & \multicolumn{2}{|c|}{ Ekim 9, 2018} \\
\hline \multicolumn{8}{|c|}{ Volues ACross, All Replicatigns } \\
\hline \multicolumn{8}{|c|}{ Unnamed Project } \\
\hline Repllcations: & Time Untis: & Hours & & & & & \\
\hline \multicolumn{8}{|l|}{ Queue } \\
\hline \multicolumn{8}{|l|}{ Other } \\
\hline Number Warting & & Averspe & Hair Wieth & $\begin{array}{c}\text { Minimum } \\
\text { Aversge }\end{array}$ & $\begin{array}{l}\text { Maximum } \\
\text { Aversge }\end{array}$ & $\begin{array}{c}\text { Minimum } \\
\text { value }\end{array}$ & $\underset{\substack{\text { Maximum } \\
\text { value }}}{ }$ \\
\hline Durak243 87. Cueve & & 0.6066 & 0,00 & 0.6866 & 0.6866 & 0.00 & $7.000 \mathrm{x}$ \\
\hline Durak249 G3.cueve & & 0.4297 & 0.00 & 0.4297 & 0.4297 & 0.00 & $5.000 x$ \\
\hline Durak25 B2 Cueve & & 0.3538 & 0.05 & 0.2284 & 0.5022 & 0.00 & $16.000 x$ \\
\hline Durak25 B5.Cueve & & 0.1229 & 0.03 & 0.07309371 & 0.1921 & 0.00 & $3.000 \mathrm{x}$ \\
\hline Durak25 G6. Cueve & & 0.2100 & 0.05 & 0.0950 & 0.2969 & 0.00 & $5.000 x$ \\
\hline Durak25 G7. Cueve & & 0.1905 & 0,02 & 0.1479 & 0.2572 & 0.00 & 11.0000 \\
\hline Durak25 K4 Cueve & & 0.2025 & 0,02 & 0.1628 & 0.2570 & 0.00 & $4.000 x$ \\
\hline Durak25 K9. Cueve & & 0.1449 & 0.05 & 0.07605377 & 0.2702 & 0.00 & $3.000 x$ \\
\hline Durak250 K8. Cueve & & 0.3438 & 0,00 & 0.3438 & 0.3438 & 0.00 & $2000 x$ \\
\hline Durak25 G1. Cueve & & 0.2518 & 0,00 & 0.2518 & 0.2518 & 0.00 & $4.000 \mathrm{x}$ \\
\hline Durak27 B6.Cueve & & 0.06559531 & 0,02 & 0.03913379 & 0.1221 & 0.00 & $2.000 \mathrm{x}$ \\
\hline Durak27 G1. Queve & & 0.02924698 & 0.01 & 0.01195818 & 0.04821788 & 0.00 & $2000 x$ \\
\hline Durak27 G2 Cueve & & 0.04961130 & 0,02 & 0.00492266 & 0.1175 & 0.00 & 20006 \\
\hline Durak27 G3. Cueve & & 0.06877694 & 0,02 & 0.02765713 & 0.1025 & 0.00 & $3.000 \mathrm{x}$ \\
\hline Durak27 G7A. cueve & & 0.01398345 & 0.00 & 0.00523403 & 0.02340732 & 0.00 & 20000 \\
\hline Durak27 G9. Cueve & & 0.3052 & 0.07 & 0.1790 & 0.4588 & 0.00 & $17.000 \mathrm{x}$ \\
\hline Durak27 K7. Cueve & & 0.04579932 & 0,01 & 0.02387957 & 0.07975776 & 0.00 & $3.000 x$ \\
\hline Durak27 K7A Cueve & & 0.0916 & 0,04 & 0.03879691 & 0.2059 & 0.00 & $4000 x$ \\
\hline Durak28 E6. Cueve & & 1.0251 & 0,15 & 0.7309 & 1.4544 & 0.00 & $14.000 x$ \\
\hline Durak28 67. Cueve & & 0.9179 & 0,08 & 0.7387 & 1.0745 & 0.00 & $20.000 \mathrm{x}$ \\
\hline Durak28 D1. Cueve & & 0.1475 & 0.03 & 0.1037 & 0.2283 & 0.00 & $4.000 x$ \\
\hline Durak28 G10 Cueve & & 0.3984 & 0.05 & 0.2394 & 0.5257 & 0.00 & $7.000 x$ \\
\hline Durak28 G12 Cueve & & 0.1395 & 0,07 & 0.03729604 & 0.2998 & 0.00 & $4.000 x$ \\
\hline Durak28 G13. Cueve & & 0.1098 & 0.05 & 0.04006582 & 0.2176 & 0.00 & $2000 x$ \\
\hline Durak28 K1.Cueve & & 0.1782 & 0.04 & 0.0953 & 0.2725 & 0.00 & $5.000 x$ \\
\hline Durak28 K5. Cueve & & 0.1243 & 0.04 & 0.05745912 & 0.2183 & 0.00 & 4.0006 \\
\hline Durak28 K6. Cueve & & 0.1265 & 0.04 & 0.05199522 & 0.1988 & 0.00 & $4.000 x$ \\
\hline Durak28 K8. Cueve & & 0.2112 & 0.04 & 0.1170 & 0.2947 & 0.00 & $4.000 x$ \\
\hline Durak29 K10.Cueve & & 0.1658 & 0.02 & 0.1008 & 0.1887 & 0.00 & $5.000 x$ \\
\hline Durak29 K7. Cueve & & 0.2757 & 0.03 & 0.2158 & 0.3245 & 0.00 & $5.000 \mathrm{x}$ \\
\hline Durak29 K7A Cueve & & 0.2559 & 0.04 & 0.1816 & 0.3257 & 0.00 & $6.000 \mathrm{x}$ \\
\hline Durak3 G8. Cueve & & 0.1907 & 0.00 & 0.1907 & 0.1907 & 0.00 & $1.000 x$ \\
\hline Durak30 K9 Cueve & & 0.1202 & 0,00 & 0.1202 & 0.1202 & 0.00 & $1.000 x$ \\
\hline Durak31 G1. Cueve & & 0.3105 & 0.00 & 0.3105 & 0.3105 & 0.00 & $6.000 x$ \\
\hline Durak32 B6.Cueve & & 0.3961 & 0,00 & 0.3961 & 0.3961 & 0.00 & 20000 \\
\hline Durak33 B3.cueve & & 0.4716 & 0,10 & 0.3058 & 0.7041 & 0.00 & 22.0006 \\
\hline Durak33 87.Cueve & & 0.7358 & 0,11 & 0.5737 & 1.0864 & 0.00 & $10.000 \mathrm{x}$ \\
\hline Durak34 K9 Cueve & & 0.1034 & 0.03 & 0.06404981 & 0.2004 & 0.00 & $2.000 \mathrm{c}$ \\
\hline Durak36 G1.Cueve & & 0.2594 & 0.00 & 0.2594 & 0.2594 & 0.00 & $5.000 x$ \\
\hline Durak37 B2A Cueve & & 0.2173 & 0.01 & 0.1834 & 0.2512 & 0.00 & $4.000 x$ \\
\hline Durak37 67. Cueve & & 0.2356 & 0.02 & 0.1833 & 0.2818 & 0.00 & 20006 \\
\hline
\end{tabular}


Table A4. Waiting Time at Station

\begin{tabular}{|c|c|c|c|c|c|}
\hline \multicolumn{2}{|l|}{$11: 13: 28$} & \multicolumn{3}{|c|}{ Queues } & Ekim 9, 2018 \\
\hline Unnamed Project & & & & & Repll|cations: 10 \\
\hline Replication 1 & Stant Time: & 0,00 & Stop Time: & 24,00 & Time Untrs: Hours \\
\hline \multicolumn{6}{|l|}{ Time } \\
\hline & & & Waring TIme & & \\
\hline Durak1 B2A. Cueve & & & 0.15 & & \\
\hline Durak1 BB. Cueve & & & 0.15 & & \\
\hline Durak1 G4 Cueve & & & 0.21 & & \\
\hline Durak1 G4A Cueve & & & 0.17 & & \\
\hline Durak1 G7A. Cueve & & & 0.06 & & \\
\hline Durak1 K10. Cueve & & & 0.05 & & \\
\hline Durak1 K3. Cueve & & & 0.13 & & \\
\hline Durak1 K4 Cueve & & & 0.17 & & \\
\hline Durak10 B6. Cueve & & & 0.17 & & \\
\hline Durak10 B8. Cueve & & & 0.05 & & \\
\hline Durak 100 K3 Cueve & & & 0.16 & & \\
\hline Durak101 K5. Cueve & & & 0.18 & & \\
\hline Durak101 K6.Cueve & & & 0.09 & & \\
\hline Durak102 B6. Cueve & & & 0.28 & & \\
\hline Durak 102 G4 Cueve & & & 0.08 & & \\
\hline Durak102 G4A Cueve & & & 0.12 & & \\
\hline Durak103 G10 Gueve & & & 0.12 & & \\
\hline Durak103 G5. Cueve & & & 0.10 & & \\
\hline Durak104 G4 Cueve & & & 0.12 & & \\
\hline Durak105 G10. Cueve & & & 0.10 & & \\
\hline Durak105 G4 Cueve & & & 0.12 & & \\
\hline Durak105 G4A Cueve & & & 0.15 & & \\
\hline Durak105 G3 Cueve & & & 0.07 & & \\
\hline Durak107 B1. Cueve & & & 0.11 & & \\
\hline Durak107 B2 Cueve & & & 0.10 & & \\
\hline Durak107 B2A.Cueve & & & 0.24 & & \\
\hline Durak107 B5. Cueve & & & 0.47 & & \\
\hline Durak107 B8. Cueve & & & 0.13 & & \\
\hline Durak107 G1. Cueve & & & 0.05 & & \\
\hline Durak107 G3 Cueve & & & 0.09 & & \\
\hline Durak107 K4 Cueve & & & 0.16 & & \\
\hline Durak107 K7. Cueve & & & 0.21 & & \\
\hline Durak107 K8. Cueve & & & 0.23 & & \\
\hline Durak108 G13. Cueve & & & 0.88 & & \\
\hline Durak108 G2 Cueve & & & 0.15 & & \\
\hline Durak108 G5. Cueve & & & 0.11 & & \\
\hline Durak108 G8. Cueve & & & 0.35 & & \\
\hline Durak108 K2 Cueve & & & 0.19 & & \\
\hline Durak108 K3. Cueve & & & 0.12 & & \\
\hline Durak109 K9. Cueve & & & 0.57 & & \\
\hline Durak11 B2 Cueve & & & 0.05 & & \\
\hline Durak11 G7. Cueve & & & 0.05 & & \\
\hline Durak110 G12 Cueve & & & 0.18 & & \\
\hline Durak111 G10. Cueve & & & 0.09 & & \\
\hline Durak111 G2 Cueve & & & 0.18 & & \\
\hline Durak111 G9. Cueve & & & 0.03 & & \\
\hline Durak111 K11. Cueve & & & 0.48 & & \\
\hline Durak111 K2 Gueve & & & 0.07 & & \\
\hline Durak111 K3.cueve & & & 0.09 & & \\
\hline
\end{tabular}


Table A5. Vehicle Occupancy

\begin{tabular}{|c|c|c|c|c|}
\hline Line Name & Passengers & Vehicle(s) & Tours & People per Tour \\
\hline B1 & 5854 & 9 & 88 & 67 \\
\hline B2 & 6008 & 22 & 218 & 28 \\
\hline B2A & 1140 & 4 & 32 & 36 \\
\hline B3 & 6138 & 22 & 218 & 28 \\
\hline B6 & 2608 & 4 & 35 & 75 \\
\hline B7 & 3527 & 6 & 58 & 61 \\
\hline B8 & 2973 & 4 & 40 & 74 \\
\hline D1 & 1152 & 3 & 32 & 36 \\
\hline G1 & 8577 & 12 & 118 & 73 \\
\hline $\mathrm{G} 2$ & 506 & 2 & 25 & 20 \\
\hline G3 & 7460 & 14 & 110 & 68 \\
\hline G4 & 5141 & 8 & 85 & 60 \\
\hline G5 & 3032 & 9 & 114 & 27 \\
\hline G4A & 2357 & 5 & 35 & 67 \\
\hline G6 & 1390 & 5 & 54 & 26 \\
\hline G7 & 3750 & 14 & 79 & 47 \\
\hline G8 & 933 & 3 & 30 & 31 \\
\hline G9 & 11874 & 20 & 165 & 72 \\
\hline G10 & 2547 & 6 & 47 & 54 \\
\hline K1 & 1477 & 3 & 40 & 37 \\
\hline K2 & 7232 & 13 & 119 & 61 \\
\hline K3 & 4710 & 10 & 74 & 64 \\
\hline K4 & 2490 & 4 & 51 & 49 \\
\hline K5 & 591 & 4 & 42 & 14 \\
\hline K6 & 873 & 3 & 42 & 21 \\
\hline K7 & 3065 & 6 & 50 & 61 \\
\hline K7A & 2170 & 5 & 36 & 60 \\
\hline K8 & 890 & 2 & 15 & 59 \\
\hline K9 & 212 & 1 & 10 & 21 \\
\hline K10 & 1850 & 7 & 96 & 19 \\
\hline
\end{tabular}

Table A6. Total Road and Fuel Consumption

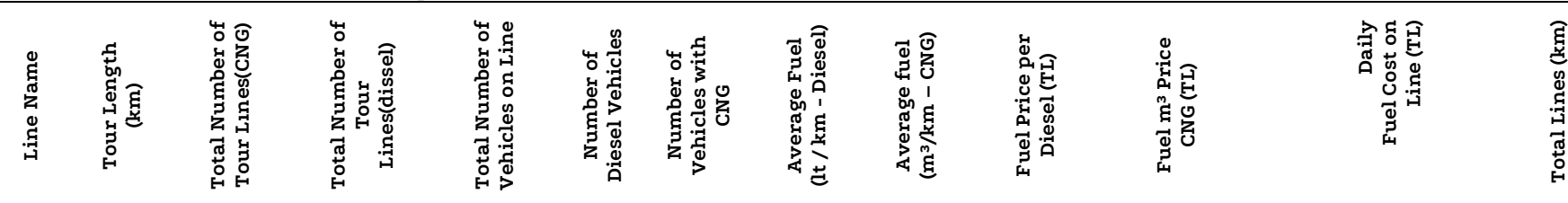

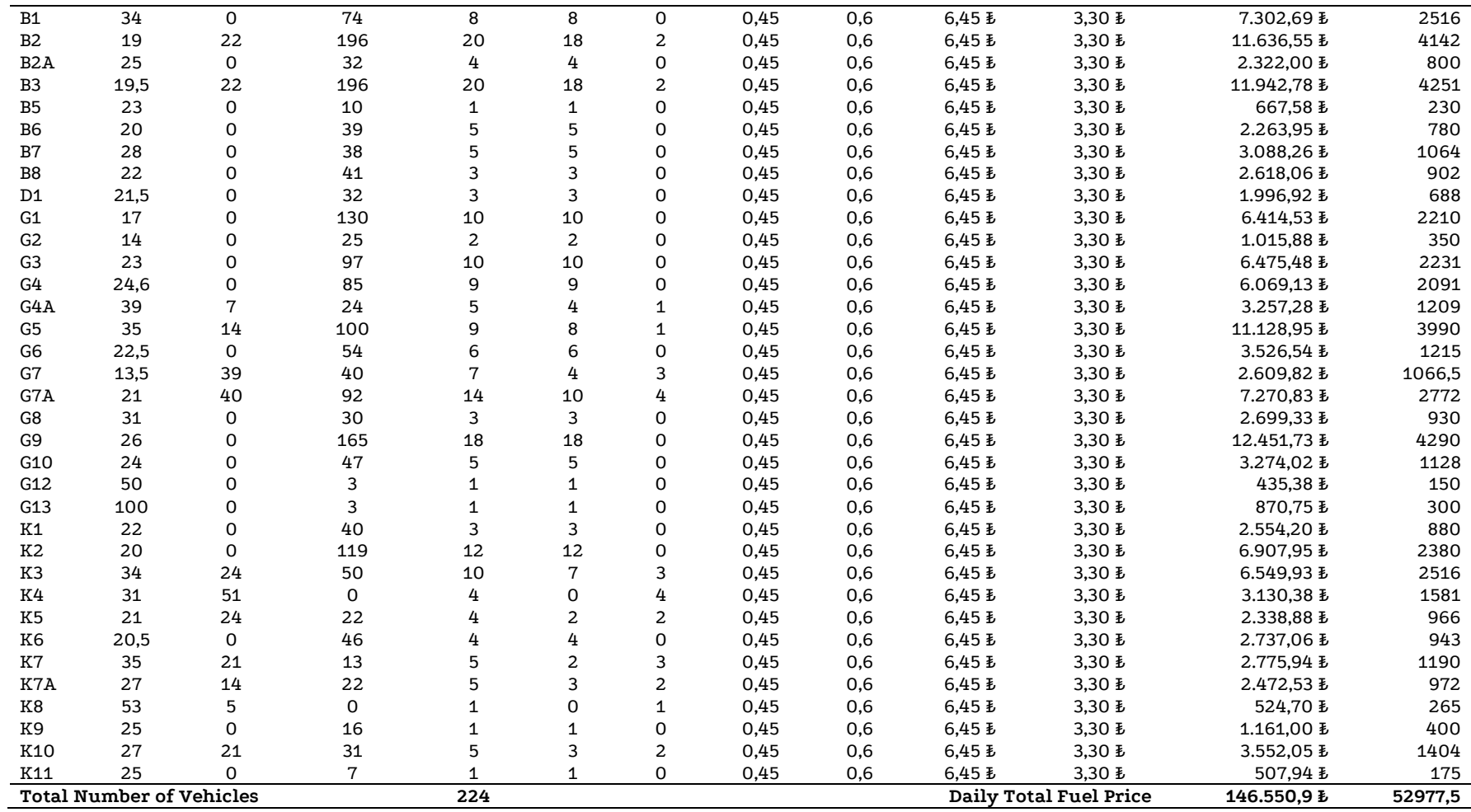

